2 Dunlop R H, Hammond P B. D-lactic acidosis of ruminants. Ann NY Acad Sci 1965; 119: 1109-32.

${ }^{3}$ Oh M S, Phelps K R, Traube M, Barbosa-Saldivar J L, Boxhill C, Carroll H. D-lactic acidosis in a man with the short-bowel syndrome. $N$ Engl J Med 1979; 301 : 249-52.

4 Duran M, van Biervliet J P G M, Kamerling J P, Wad- man S K. D-lactic aciduria; an inborn error of metabolism? Clin Chim Acta 1977; 74: 297-300.

Correspondence to Professor Dr H H van Gelderen, Department of Paediatrics, University Hospital, Leiden, The Netherlands.

\title{
Hypoproteinaemia, oedema, and anaemia: an unusual presentation of cystic fibrosis in dizygotic twins
}

\author{
I BLUMENTHAL AND D W FIELDING \\ Department of Paediatrics, Chester City Hospital, Chester
}

SUMMARY The rare combination of oedema, hypoproteinaemia, and anaemia as a presenting feature of cystic fibrosis in dizygotic twins of opposite sex is described. The features of this syndrome together with pathogenesis, treatment, and prognosis are discussed.

Cystic fibrosis seldom affects both members of a dizygotic twin pair. This paper reports twins of opposite sex with the unusual presentation of hypoproteinaemia, anaemia, and oedema.

\section{Case report}

Dizygotic twins were born by vaginal delivery to a 29-year-old white primigravida after an uneventful pregnancy and labour. Their estimated gestational age was 37 weeks. The first twin was a boy weighing $2.46 \mathrm{~kg}$, and the second a girl weighing $1.98 \mathrm{~kg}$. Both were breast fed with occasional supplements of cows' milk (SMA Gold Cap). Weight gain was slow despite voracious appetites and satisfactory calorie intakes. Screening tests to exclude infection and metabolic errors showed a urinary infection in twin 1 . Treatment produced no improvement. The twins were discharged at 4 weeks; it had been noted that they cried excessively and did not settle after feeds. At discharge their respective weights were 2.52 and $2.38 \mathrm{~kg}$. Assessment at 7 weeks showed minimal weight gain (Figure); physical examination was normal.

At 9 weeks admission was precipitated by the development of anasarca and pallor. On examination each twin was pale and had generalised pitting oedema. With the exception of slight jaundice no other abnormality was noted. Blood pressures were normal. There was no proteinuria. Investigations showed anaemia and hypoproteinaemia; both twins were transfused. The results of investi- gations are shown in the Table. The consistent increase in sweat chloride concentration together with absent faecal trypsin led to the diagnosis of cystic fibrosis. Chest $x$-rays were normal. Chromosome analysis was $46 \mathrm{XY}$ (twin 1) and $46 \mathrm{XX}$ (twin 2).

13 weeks after birth treatment with pancreatic extract (Pancreatin BP) and flucloxacillin was begun. The formula (SMA) used to supplement breast feeding was replaced by a high protein
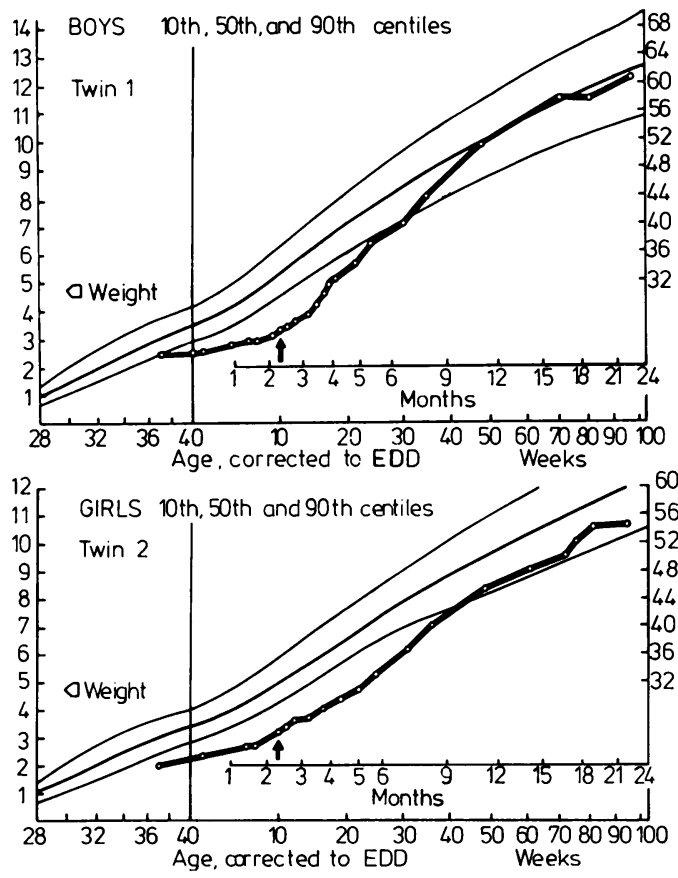

Figure Weights of twins plotted on growth charts. Arrows indicate start of pancreatic extract and high protein formula. 
Table Investigations on admission at 9 weeks

\begin{tabular}{lcc}
\hline & Twin 1 & Twin 2 \\
\hline Bilirubin ( $\mu$ mol/l) & 129 & 140 \\
$\quad$ total & 99 & 120 \\
$\quad$ Andirect & 279 & 301 \\
Alkaline phosphatase (IU/1) & 47 & 54 \\
Alanine transaminase (IU/l) & 44 & 46 \\
Sweat chloride (mmol/1) & 106 & 108 \\
& 89 & 93 \\
Haemoglobin (g/dl) & 80 & 99 \\
Reticulocytes (\%) & $6 \cdot 3$ & $7 \cdot 5$ \\
Total plasma protein (g/l) & $4 \cdot 5$ & - \\
Serum albumin (g/l) & 39 & 45 \\
Urine protein & 23 & 23 \\
Stool occult blood & Negative & Negative \\
\hline
\end{tabular}

Conversion SI to traditional units-bilirubin: $1 \mu \mathrm{mol} / 1=0.0585 \mathrm{mg} /$ $100 \mathrm{ml}$.

formula (Prosol followed by Galactomin 17). Loss of oedematous fluid led to a slight reduction in weight initially, but this was soon followed by a steady gain. They cried less and settled into a regular feeding routine. Haemoglobin, protein, and bilirubin values returned to normal and eventually the high protein formula was stopped. Subsequently both twins developed respiratory symptoms; however when last seen aged 2 years they were thriving with weights between the 10th and 50th centiles (Figure).

\section{Discussion}

The combination of hypoproteinaemia, oedema, and anaemia is an uncommon presentation of cystic fibrosis. 81 cases have been reported and these include only 2 reports of this syndrome in each of identical twins. ${ }^{1-2}$ This seems to be the first report of twins of opposite sex. The rarity can best be appreciated by estimating the incidence of cystic fibrosis in twins. The frequency of monozygotic twinning is about 3 per thousand pregnancies, dizygotic twinning occurring 2-3 times more often in Caucasians. Based on the assumption that 1 in 22 Caucasians are cystic fibrosis carriers (hererozygotes), we calculated that after random mating the chance of monozygotic twins with cystic fibrosis would be about 1 in 0.6 million pregnancies; conversely the chance of dizygotic twins with cystic fibrosis would be about 1 in 0.75 to 1.25 million pregnancies.

Oedema within the first 3 months may be sufficiently severe to produce shock. ${ }^{1}$ Despite a good appetite and adequate calorie intake there is usually poor weight gain before the development of oedema. The syndrome has been reported in breast-fed infants more often than those fed cows' milk formula and it is suggested that the lower protein content of human compared with cows' milk predisposes to hypoproteinaemia if malabsorption already exists. ${ }^{3}$ It remains to be seen whether this presentation of cystic fibrosis will become more common with the widespread use of low protein modified cows' milk.

The precise aetiology of hypoproteinaemia is yet to be established. It may be that the milk intake is insufficient to compensate for the protein loss due to malabsorption. It has been established that there is no leakage of protein into the gut. ${ }^{1}$ Liver dysfunction is unlikely to be the cause as liver function tests and biopsy may be normal ${ }^{1}$ and, if abnormal, there is a rapid reversion to normality with a change in diet and correction of the hypoproteinaemia. ${ }^{4-5}$ The cause of anaemia in this syndrome is also not clear. The anaemia is normochromic, normocytic, and nonhaemolytic. Vitamin E deficiency is usually present in cystic fibrosis and produces a haemolytic anaemia; it is therefore unlikely to be a contributory factor. Shahidi et al. ${ }^{6}$ attributed the anaemia to protein deficiency which led to a reduced ironbinding capacity and, in turn, to a low serum iron concentration. However, Paxson and Lock ${ }^{1}$ found a normal serum iron level with increased deposition of iron in the marrow, suggesting a defect in haemoglobin synthesis rather than insufficient iron transport. The introduction of a high protein diet is rapidly followed by a reticulocytosis and a rise in haemoglobin value. ${ }^{6}$

Where there is oedema, the diagnosis of cystic fibrosis is best made by pancreatic enzyme assay as sweat test results may be unreliable. ${ }^{7}$ In this case it was felt that duodenal intubation was not justified in view of the classical clinical picture and persistent increase in sweat chloride after the oedema had gone. Treatment consists of high protein diet and pancreatic extract, which initially produce loss of oedema and subsequently a weight increase. Recent reports suggest that provided appropriate treatment is given early, these patients improve and thrive as well as those presenting in more conventional ways during infancy.

We thank Mrs J Doyle for typographical assistance.

\section{References}

1 Paxson C L, Jr, Lock J L. Letter: Idiopathic hypoproteinemia in twins. JAMA 1974; 230: $1257-8$.

2 Bass N H, Miller A A. Cystic fibrosis presenting with anemia and hypoproteinemia in identical twins. Pediatrics 1977; 59: 126-7.

3 Lee P A, Roloff D W. Hypoproteinemia and anemia in infants with cystic fibrosis: presenting symptom complex often misdiagnosed. In: Gellis S S, ed. Yearbook of Pediatrics. Chicago: Year Book Medical Publishers, 1975: 209-10. 
4 Dolan T F, Jr, Rowe D S, Gibson L E. Edema and hypoproteinemia in infants with cystic fibrosis. Clin Pediatr (Phila) 1970; 9: 295-7.

5 Lee P A, Roloff D W, Howat W F. Hypoproteinemia and anemia in infants with cystic fibrosis. JAMA 1974; 228: $585-8$.

${ }^{6}$ Shahidi N T, Diamond L K, Shwachman H. Anemia associated with protein deficiency. A study of two cases with cystic fibrosis. $J$ Pediatr 1961; 59: 533-42.

7 MacLean W C, Jr, Tripp R W. Cystic fibrosis with edema and falsely negative sweat test. $J$ Pediatr $1973 ; 83$ : 86-8.

Correspondence to Dr I Blumenthal, Department of Paediatrics, St James University Hospital, Leeds LS9 7TF.

\title{
Porencephalic cysts after amniocentesis
}

\author{
S YOUROUKOS, F PAPADELIS, AND N MATSANIOTIS
}

First Department of Paediatrics of Athens University, Aghia Sophia Children's Hospital, Athens, Greece

SUMMARY An infant with porencephalic cysts associated with midtrimester amniocentesis is reported. CNS anomalies after amniocentesis have not been reported in live neonates.

Midtrimester amniocentesis can be a helpful diagnostic procedure, but several complications have been reported. ${ }^{1}$ An injury to the fetus is rare but such injuries have included skin scars, bowel obstruction, ileocutaneous fistula, cardiac tamponade, laceration of the spleen, ocular trauma, pneumothorax, cord haematoma, fetal haemorrhage, and limb deformity.

\section{Case report}

A 5-month-old girl was seen because of unusual eye movements. Both parents were $\beta$-thalassaemia trait carriers but were otherwise healthy. Amniocentesis was performed in the 18th week of gestation to find out the haematological status of the fetus. Placental aspiration was uneventful. An 18 gauge needle with trochar was used and several specimens of fetal blood were obtained from the placenta. Haematological examinations indicated that the fetus was normal.

The baby was delivered at term by caesarean section because of fetal distress. She was cyanotic at birth and required resuscitation. Birthweight was $3 \cdot 2 \mathrm{~kg}$. Since birth frequent, rapid, jerky movements of her eyes have been noticed, lasting 3 to 4 seconds. On examination the infant was alert and smiled responsively. Two small $(8 \times 5 \times 5 \mathrm{~mm})$ subcutaneous nodules were noticed, one in the right posterior temporal area and the other in the right occipital area. Both nodules were present at birth. The anterior one was hard and painless with scar tissue on the overlying skin. The posterior one was painful and on the overlying skin there was a narrow sinus surrounded by scar tissue. A slight bloody discharge was produced from this sinus during the first days of life. Head circumference was $41 \mathrm{~cm}$ (25th centile). There was a moderate plagiocephaly. Transillumination of the skull showed an area of increased transillumination over the right occipito-temporal area. No optokinetic nystagmus could be produced and the patient had a probable left visual field defect. Fundi were normal. There were frequent, jerky, vertical eye movements, lasting 3 or 4 seconds, and resembling opsoclonus (dancing eyes). These movements were not accompanied by any movement of the trunk or limbs. The patient controlled her head well, but there was a significant degree of torticollis. She also had a slight left hemiparesis.

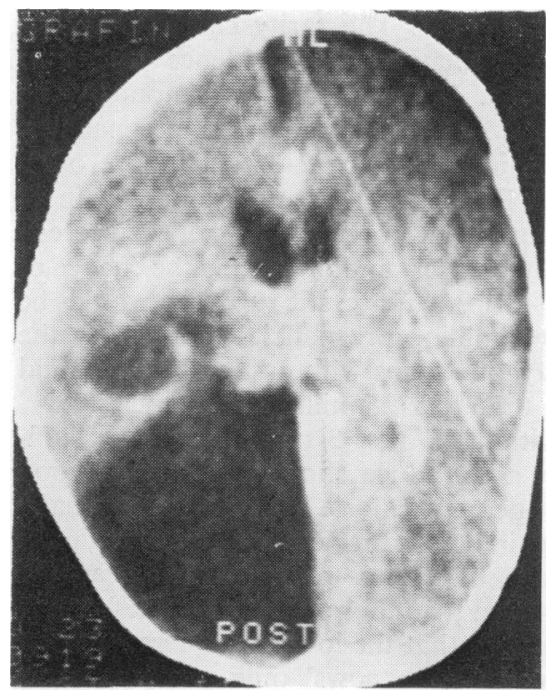

